\title{
Implementation of a Curriculum Management Tool: Challenges Faced by a Large Australian University
}

\author{
Jennifer Lai ${ }^{1}$, Leigh Wood ${ }^{1} \&$ Mauricio Marrone ${ }^{2}$ \\ ${ }^{1}$ Faculty of Business and Economics, Macquarie University, Australia \\ ${ }^{2}$ Learning and Teaching Centre, Macquarie University, Australia \\ Correspondence: Jennifer Lai, Faculty of Business and Economics, E4A, Macquarie University, NSW 2109, \\ Australia. Tel: 61-2-9850-4754. E-mail: jennifer.lai@mq.edu.au
}

$\begin{array}{lc}\text { Received: August 21, } 2012 & \text { Accepted: September 24, } 2012 \quad \text { Online Published: October 31, } 2012 \\ \text { doi:10.5539/ass.v8n14p28 } & \text { URL: http://dx.doi.org/10.5539/ass.v8n14p28 }\end{array}$

\begin{abstract}
This paper describes how a large Australian university implemented a new curriculum management tool UNITS. UNITS is an online repository of unit guides and a curriculum mapping tool. We analyze the advantages of using a university-wide curriculum management tool and the change management processes used to develop the bespoke tool. Staff development in the use of the tool has led to more thoughtful use of learning and teaching activities and better linking of learning outcomes with assessment. To ensure a smooth transition, faculty were supported throughout the process of implementation. Drop-in clinics, video clips, discipline-specific implementation guides as well as a UNITS help page were provided. This paper contributes to the understanding of the challenges in setting up and implementing a large-scale curriculum management tool in a university. Challenges including increased workload, intellectual property concerns, impact on academic freedom and technological issues are discussed.
\end{abstract}

Keywords: curriculum management tool, assessment and learning outcomes, technological adoption, UNITS, higher education

\section{Introduction}

A curriculum is a combination of various relationships including educational strategies, course materials, learning outcomes, assessment tasks, graduate capabilities, educational environment and students' learning style (Harden, 2001; Bath, Smith, Stein, \& Swann, 2004; Ornstein \& Hunkins, 2004). Managing a curriculum is not an easy task. One of the tools that can provide assistance to curriculum management is curriculum mapping. Curriculum mapping is an effective instrument for improving teaching and learning (Jacobs, 2004): students can identify the learning requirements, whereas staff can have a clearer picture about their overall duties. It also helps the teaching faculty identify alignment, gaps and strengths within a curriculum (Liu, Wrobbel, \& Blankson, 2010). With technological advancement, curriculum management and mapping can nowadays be more dynamic and interactive (Henson, 2010). Online curriculum management tools have been adopted by universities in different disciplines like medicine, engineering, social sciences, sciences and business (Cottrell, Linger, \& Shumway, 2004; von Konsky et al., 2006; Watson et al., 2007).

In Australia, the application of online curriculum management systems has been in place for a decade (Watson et al., 2007). For example, in 2001 the Faculty of Medicine of the University of New South Wales developed a web-enabled curriculum management system to manage graduate capabilities, content, learning outcomes and activities, and assessment in their undergraduate programs (Watson et al., 2007). Michael (2007) also reports on a successful implementation at University of Wollongong of an online curriculum management system to perform and enhance curriculum mapping. While the range of systems used in the management of curricula continues to grow, documentation of these systems remains limited and piecemeal (Lever, Gluga, \& Kay, 2011). More studies on the processes of implementation of online curriculum management tools would be beneficial.

In 2011, a new web-based curriculum management tool (UNITS) was set up by Macquarie University, a large Australian university. UNITS is being used mainly for publishing online unit guides; communicating assessment, learning outcomes and graduate capabilities; and for curriculum mapping purposes. All undergraduate unit guides for Session 2, 2012, were published using the UNITS system. There are many potential benefits of the 
system, including facilitation of curriculum review, accreditation reporting and better information for students, lecturers and administrators.

The objectives of this paper are to share the experience of how Macquarie University implemented a new curriculum management tool, the supports provided and the challenges faced throughout the whole implementation process. It is believed that this experience can be transferred to other universities that are planning for or in the process of launching an online curriculum management tool. In the following sections, we will first discuss the literature related to curriculum management and technological change in higher education; then we will describe the UNITS system, the implementation phases and the quality assurance steps in detail. Finally, we will investigate the challenges we encountered during the process of implementation.

\section{Literature Review}

Assessment is a central feature of teaching and the curriculum (Boud \& Associates, 2010) as it drives what students learn (Wood, 2012). Displaying assessment information in a systematic way with the help of technologies can enrich students' learning experience (Coates, James, \& Baldwin, 2005). It is therefore critical to the success of students' studies that they have access to detailed information about the assessments.

\subsection{Assessment and University-wide Curriculum Management Tools}

Assessment tasks determine what students learn and form part of the students' learning journey in a unit and the whole program (Wood, Thomas, \& Rigby, 2011; Wood, 2012). Assessment can be considered at four levels class, unit, program and accreditation. Assessment within each level is linked (Figure 1), and a shared understanding of the different components within each level helps promote and maintain alignment in assessment. A program (used here as a synonym for a course) is a connected series of units that make up a major, specialisation or degree. Using Macquarie University as an example, there are generally eight units for majors, four units for specialisations and about twenty-four units for undergraduate degrees (Wood, 2012). Setting assessment tasks at an appropriate level allows students to demonstrate their achievement of the required standards. With the help of a university-wide curriculum management tool, the management of assessment practices can be made more effective for the ultimate benefit of students.

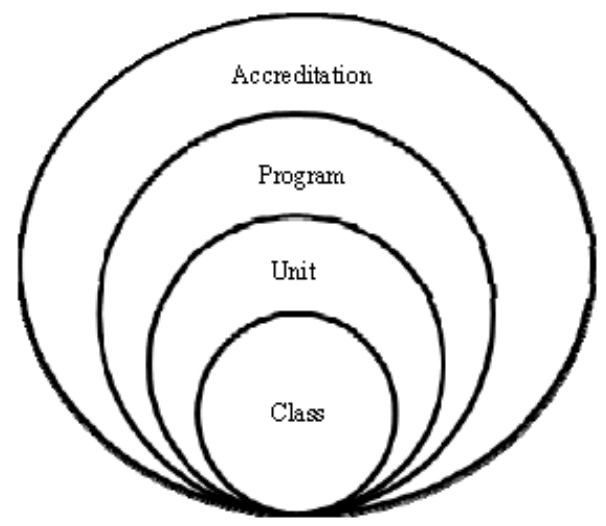

Figure 1. Relationship between assessment at different levels

Nowadays, new technologies offer tremendous power to assist with the design and potential changes to the curriculum and other essentials in higher education, including assessment, learning outcomes, graduate capabilities and so on (Henson, 2010). However, despite the extraordinary potential for the use of technology in the field of education, many teachers are still reluctant to embrace technological innovations (Buckenmeyer, 2008). In the following section, we will discuss the barriers to and conditions promoting technological adoption.

\subsection{Barriers to Change}

Researchers have investigated the barriers to adopting new technologies for decades (Davis, 1989; Rogers, 2000; Venkatesh \& Davis, 2000). One of the central theories in technology adoption research is the Technology Acceptance Model (TAM) (Davis, 1989). TAM suggests two beliefs - perceived usefulness and perceived ease of use - to explain a user's attitude and intention to use a new system. Indeed, since its inception, TAM has received extensive empirical support through replications (Venkatesh, Morris, Davis, \& Davis, 2003). Perceived usefulness is 'the degree to which a person believes that using a particular system would enhance his or her job performance' (Davis, 1989, p.14), while perceived ease of use is the 'degree to which a person believes that using a particular system would be free of effort' (Davis, 1989, p. 14). Perceived usefulness and perceived ease 
of use may contribute towards performance, whilst the lack of these positive attitudes can cause frustration and weaken the adoption of technology (Venkatesh \& Davis, 2000). In addition to perceived usefulness and perceived ease of use, researchers have identified further barriers to the adoption of technology in higher education, such as insufficient provision of technological support, financial support and infrastructure; teachers' lack of knowledge; and technophobia (Rogers, 2000; Al-Senaidi, Lin, \& Poirot, 2009; Abrahams, 2010).

\subsection{Conditions Promoting Change}

To facilitate change and system adoption, researchers believe that the availability of system support is critical (Karahanna \& Straub, 1999); such support includes help desks, online support services, customized support and other facilities (Ralph, 1991). According to Maney (1999) timely and high-quality system support can contribute significantly to the adoption of a new system, while Vannatta and Fordham (2004) suggest that it is critical that sufficient time must be given to users to learn new technologies. Other studies show that there is a positive relationship between the time invested in learning and the adoption of new technology (Liu, Maddux, \& Johnson, 2004). Finally, the attitude of users towards technology is a reliably strong predictor of technology acceptance and adoption (Craig, 2006); therefore encouraging a positive attitude and the perception of usefulness of the system are essential for successful adoption.

\section{Macquarie University - UNITS}

In this section, we wish to introduce the system developed at Macquarie University, describe it and show the phases of implementation. We also talk about the support given to staff with regards to the implementation of this new tool.

\subsection{Description}

The UNITS system implemented at Macquarie University is a web-based tool for:

1) creating, reviewing and publishing unit guides;

2) ensuring unit guides are accessible to students and the general public;

3) displaying how units and programs provide opportunities for students to meet the university's graduate capabilities;

4) collecting and displaying unit assessment information;

5) collecting and displaying unit learning outcomes;

6) linking learning outcomes and assessments to the University's graduate capabilities;

7) specifying the interpretation of graduate capabilities and

8) evaluating degree and program coverage of graduate capabilities.

UNITS is composed of several logical components (in rectangles in Figure 2) and interacts with several other key systems (in ovals in Figure 2). A detailed description of the logical components in UNITS is provided in Table 1. 


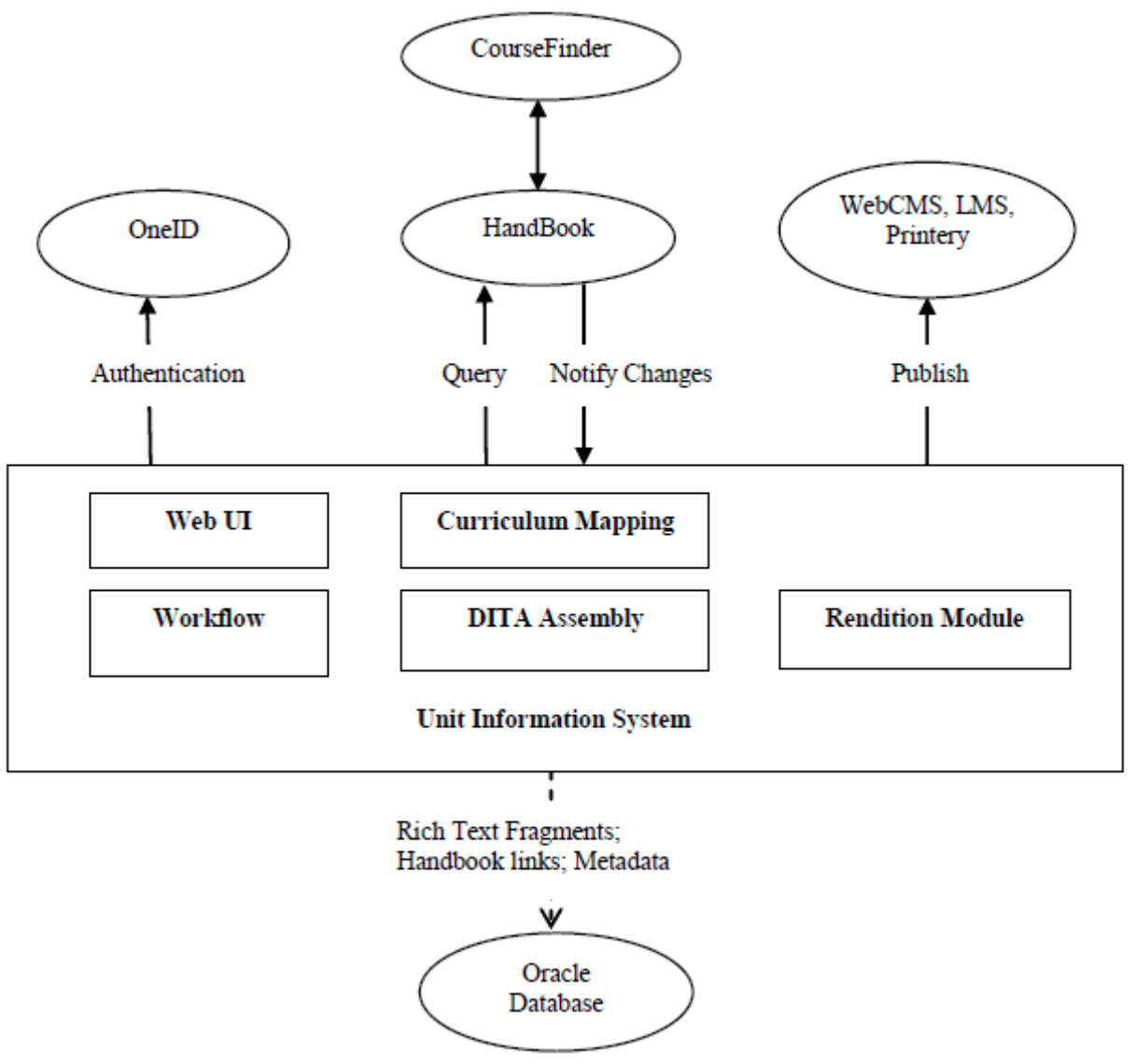

Figure 2. UNITS system

Table 1. Components of the UNITS system

\begin{tabular}{ll}
\hline Component & \\
UNITS & Information \\
System &
\end{tabular}

Web User Interface (UI)

\section{Curriculum Mapping}

Workflow

Darwin

Typing

(DITA) Assembly

Information
Architecture

\section{Rendition Module}

\section{Description}

The overall system. Built as a web-app on a Rails/Apache/Oracle/Linux stack.

Main user interface for the application, for authoring and publishing unit guides. Information is edited as Rich Text fragments that will be constructed later into a Unit Guide.

Component used to author, analyse and manage the curriculum mapping between Graduate Capabilities, Learning Tasks, Assessments Tasks and Learning Outcomes.

Module for handling guide review and approvals for publication.

Manages the construction of a DITA output from the fragments.

Responsible for rendering the DITA document into PDF, eText, ePub etc., and for pushing it out to the Web Content Management System (WebCMS), Printery and the Learning Management System (LMS).

UNITS interacts with other services provided by Informatics (the central business that creates information technology services for Macquarie University) such as the HandBook (Macquarie University's official source of information about undergraduate, graduate and postgraduate studies), and with OneID (Macquarie's single login password maintenance system for both students and staff).

The desired outcomes of the system include: 
1) Development of an application for preparing and publishing unit guides, and mapping units against graduate capabilities.

2) All undergraduate unit guides from Session 2, 2012, onwards should be prepared and published using the application.

3) All undergraduate programs can be reported on for coverage of graduate capabilities.

\subsection{Implementation}

UNITS was launched on the $1^{\text {st }}$ of November, 2011. An announcement about its launch was made through an email sent to all staff of the University. Following this, implementation was executed through a phase approach; the ten phases are described below:

\section{Phase 1: Training the movers}

Unit guides from previous offerings were entered into the system so that unit convenors can have information about their units prepopulated. The team in charge of prepopulating units was trained in February, and there was at least one person representing each Faculty. This team and the project manager maintained constant communication.

\section{Phase 2: Assigning department managers in each Faculty}

A list of department managers of UNITS was sent to the Associate Deans of Learning and Teaching for their review. After being appointed as department managers, they were invited to take part in training.

\section{Phase 3: Training of department managers}

Three opportunities for training were provided at the start of Semester 1 for department managers. On average two department managers were assigned to each department. Over 60 department managers were assigned, and half of those invited participated in the training.

Phase 4: Holding information sessions and 'road shows'

Two University-wide sessions where held and a University-wide email was sent to invite convenors to learn about the UNITS system. The first information session was held on 20 March, and it was recorded and then made available on the UNITS website. The Associate Deans of Learning and Teaching and the project manager did 'road shows' where they visited departmental meetings to introduce unit convenors to UNITS. Departments from all Faculties were able to invite the project manager to come and present the system to them.

\section{Phase 5: Quick guides and screen capture videos made available}

Self-help was made available through the UNITS help page.

Phase 6: Ensuring that unit convenors were assigned to units

Two months before the start of semester three out of four departments had more than $70 \%$ of the unit convenors assigned to a unit. This was significant, because convenors would only be able to edit the unit guides that were assigned specifically to them. At the start of the semester, three out of four Faculties had assigned more than $90 \%$ of the units to a convenor.

\section{Phase 7: Integration of UNITS into the Learning Management System (LMS)}

To reduce duplication of work, convenors could create an automatic link from their LMS to their unit guide in UNITS.

\section{Phase 8: Workshop on writing unit guides}

This workshop was delivered to University academics to provide them with guidelines and strategies for writing effective unit guides. The workshop concentrated as well on aligning assessments, principles of assessment task design and assessment policies.

Phase 9: Drop-in clinics

Five weeks before the semester started, one-on-one support was provided to convenors who came to the drop-in clinics; these were offered from 9am to $5 \mathrm{pm}$ from Monday to Friday.

Phase 10: Announcing the service to students

On the day the semester started, an email message was sent to all undergraduate students informing them that they could now access their unit guides in UNITS. Announcements also went out on Twitter and Facebook. 


\subsection{Support and Guidelines for Staff}

Researchers like Ralph (1991) argue that, to facilitate technological adoption, system supports like a help desk, online support services, and customized support are critical. During the implementation process at Macquarie University, relevant training, information sessions, road shows, quick guides and video clips had been given to the staff to familiarize themselves with the system. In addition to system support, guidelines were given to the staff for preparing the contents of different sections of their online unit guides and pedagogical information, such as how to develop assessment tasks and align them with learning outcomes and graduate capabilities. It is mentioned in the previous section that assessment is critical in the student's learning process. The Faculty of Business and Economics at Macquarie University published a booklet, How to Align Assessment: Learning through a Program Approach (Wood, 2012), to provide information to support the development and implementation of assessment. Descriptions of ten types of assessment are presented in the booklet. These assessments have been designed to measure the achievement of learning outcomes to a standard. In addition, the University's Learning and Teaching Centre has developed resources on how to develop learning outcomes and how to address graduate capabilities in units.

Curriculum mapping is one of the most critical features of UNITS. Mapping involves identifying where graduate capabilities are actively taught and assessed in a unit and it incorporates learning outcomes and assessment tasks. Leaflets showing examples of learning outcomes in relation to graduate capabilities were provided to staff. In addition, personal assistance on how to do the curriculum mapping was offered to staff, so that they would be less likely to perceive the system as being too difficult to use.

\section{Discussion}

To make sure the unit guides provide concise and consistent public information, steps were taken to assure their quality. They are governed by the Unit Guide Policy of Macquarie University, and their content will be reviewed periodically.

\subsection{Quality Assurance}

Before submitting a unit guide for approval, staff were advised to review their unit guides with a colleague familiar with the discipline area. In addition, departments set up committees to oversee the unit guide publication process and to provide personal support when needed. The Learning and Teaching Department of each Faculty provided advice and assistance to the Heads of Department regarding the development, approval and review of unit guides. Online unit guides were revised and approved by Heads of Department through the UNITS system. To ensure that students were consistently kept informed, if a published unit guide needed to be amended, then staff were required to provide a description of the changes. The description would be displayed to students in the new version of the unit guide, to enable them to quickly identify any changes that they needed to be aware of.

UNITS can also help with facilitating and preparing for the accreditation process for programs. The capacity for curriculum mapping in the UNITS system is particularly suitable for degree and curriculum improvement, and the curriculum mapping report generated by the system provides a way to see the coverage of all the University's graduate capabilities in a degree, major or program of study. Mapping of assessment tasks in relation to learning outcomes and graduate capabilities ensures that the University delivers quality programs that meet external standards such as the Australian Qualifications Framework or the requirements of professional associations.

\subsection{Challenges}

Implementation of changes is never easy, and various factors may influence the adoption of a new system. Four key issues that affect the adoption of UNITS were identified: increased workload, intellectual property concerns, impact on academic freedom and technological issues.

\subsubsection{Increased Workload}

In 2012, Macquarie University changed several of their learning management tools including migrating to systems like iLearn (learning management system), Echo360 (lecture recording system) and iTeach (online enrolment system). Staff were not all willing to adopt these new systems, because some considered that the change might significantly increase their workload, and/or they were concerned about the additional time required for dealing with the new systems. To reduce the workload for staff in dealing with UNITS, unit guides from previous offerings were entered into the system so that unit convenors could have relevant information about their units prepopulated.

In addition, it is essential that the usefulness of using a new system is emphasized because this factor has a strong, direct impact on the intention of adopters to use the technology (Dwivedi, Lal, \& Williams, 2009). It was 
highlighted to staff that once the system had been set up for the first time, it will take only minimal effort to edit the online unit outlines in the future because there is a 'clone' function in the system that allows them to import and export (clone) one unit guide to another.

\subsubsection{Intellectual Property Concerns}

Some staff were reluctant to use the new UNITS system due to concerns about copyright and intellectual property rights for course materials in the online unit guides: they felt uneasy with the increased visibility and accountability of an online environment. Twigg (2000) has also discussed issues relevant to the ownership of online materials relating to courses; however, it is stated clearly in Macquarie's unit guide policy that they all remain the property of the University. Guidelines for the UNITS system included a reminder to staff not to put materials on UNITS that have copyright licensing and intellectual property restrictions. Detailed assessment questions and activities were password protected and made available only to those who had authorised access (that is, enrolled students and University staff).

\subsubsection{Impact on Academic Freedom}

UNITS can assist in the curriculum management of the programs and degrees offered at the University. However, some staff were worried that the implementation of a unified system could restrict academic freedom. That is, they said they would not have as much room to manoeuvre with the unit guides, and could not actively and flexibly develop unit guides that were tailor-made for their students. There is some truth in this, however, surveys of students show that they want consistency and predictability in their learning (Mackey \& Ho, 2008).The UNITS system forces a consistent approach while still allowing some freedom with the design of assessment and learning and teaching activities.

\subsubsection{Technological Issues}

Technology-related errors made some staff less accommodating with regards to the new system. For instance, some staff received an error message when they logged in. Other staff would like to have some amendments of the user interface because they considered that the interface was not very user friendly. As well, some users suggested that new system features should be introduced, such as the ability to select different font styles. A lot of feedback has been received during the whole process and it is expected that staff will have a better experience with UNITS in the next semester after improvements have been made.

\section{Conclusion}

This paper describes how Macquarie University developed and implemented a new curriculum management tool - UNITS. This system will assist in the development, implementation and evaluation of the curriculum at a university level in a convenient and timely manner. It will also assist students to manage their learning and workload with greater ease. Guidelines and assistance were given to staff to make sure the implementation process was smooth, and quality assurance measures were implemented during the whole process. Understanding of the challenges that influence the adoption of the new system is essential for improvement in the long term. It is believed that the experience of the adoption of a university-wide curriculum management tool in Macquarie University can be transferred to other universities that are planning or implementing an online curriculum management tool.

\section{Acknowledgements}

Thank you to Glyn Mather for her assistance with this paper.

\section{References}

Abrahams, D. A. (2010). Technology adoption in higher education: A framework for identifying and prioritizing issues and barriers to adoption of instructional technology. Journal of Applied Research in Higher Education, 2(2), 33-49. http://dx.doi.org/10.1108/17581184201000012

Al-Senaidi, S., Lin, L., \& Poirot, J. (2009). Barriers to adopting technology for teaching and learning in Oman. Computers \& Education, 53, 575-590. http://dx.doi.org/10.1016/j.compedu.2009.03.015

Bath, D., Smith, C., Stein, S., \& Swann, R. (2004). Beyond mapping and embedding graduate attributes: Bringing together quality assurance and action learning to create a validated and living curriculum. Higher Education Research \& Development, 23(3), 313-328. http://dx.doi.org/10.1080/0729436042000235427

Boud et al. (2010). Assessment 2020: Seven propositions for assessment reform in higher education. Sydney: 
Australian Learning and Teaching Council.

Buckenmeyer, J. (2008). Revisiting teacher adoption of technology: Research implications and recommendations for successful full technology integration. College Teaching Methods \& Styles Journal, 4(6), 7-10.

Coates, H., James, R., \& Baldwin, G. (2005). A critical examination of the effects of learning management systems on university teaching and learning. Tertiary Education and Management, 11, 19-36. http://dx.doi.org/10.1080/13583883.2005.9967137

Cottrell, S., Linger, B., \& Shumway, J. (2004). Using information contained in the curriculum management information tool (CurrMIT) to capture opportunities for student learning and development. Medical Teacher, 26(5), 423-427. http://dx.doi.org/10.1080/0142159042000218650

Craig, D. J. (2006). Why is dissemination so difficult? The nature of teacher knowledge and the spread of curriculum reform. American Educational Research Journal, 43(2), 257-293. http://dx.doi.org/10.3102/00028312043002257

Davis, F. D. (1989). Perceived usefulness, perceived ease of use and user acceptance of information technology. MIS Quarterly, 13(3), 319-339. http://dx.doi.org/10.2307/249008

Dwivedi, Y. K., Lal, B., \& Williams, M. D. (2009). Managing consumer adoption of broadband: Examining drivers and barriers. Industrial Management \& Data Systems, 109(3), 357-369. http://dx.doi.org/10.1108/02635570910939380

Harden, R. M. (2001). AMEE Guide No. 21: Curriculum mapping: A tool for transparent and authentic teaching and learning. Medical Teacher, 23, 123-137. http://dx.doi.org/10.1080/01421590120036547

Henson, K. T. (2010). Curriculum planning: Integrating muticulturalism, constructivism, and education reform. USA: Waveland Press, Inc.

Jacobs, H. H. (2004). Getting results with curriculum mapping. Alexandria, VA: Association for Supervision and Curriculum Development.

Karahanna, E., \& Straub, D. W. (1999). The psychological origins of perceived usefulness and ease-of-use. Information and Management, 35, 237-250. http://dx.doi.org/10.1016/S0378-7206(98)00096-2

Lever, T., Gluga, R., \& Kay, J. (2011). Working from the evidence of prior art and experience in curriculum database development. Paper presented at the ASCILITE Conference, Hobart, Tasmania: Australia.

Liu, L., Maddux, C., \& Johnson, L. (2004). Computer attitude and achievement: Is time an intermediate variable? Journal of Technology and Teacher Education, 12(4), 593-607.

Liu, M., Wrobbel, D., \& Blankson, I. (2010). Rethinking program assessment through the use of program alignment mapping technique. Communication Teacher, 24(4), 238-246. http://dx.doi.org/10.1080/17404622.2010.513002

Mackey, T. P., \& Ho, J. (2008). Exploring the relationships between Web usability and students' perceived learning in Web-based Multimedia (WBMM) tutorials. Computers \& Education, 50, 386-409. http://dx.doi.org/10.1016/j.compedu.2006.08.006

Maney, J. K. (1999). The role of technology in education: Reality, pitfalls, and potential. In G. J. Cizek (Ed.), Handbook of educational policy (pp. 387-415). San Diego, CA: Academic. http://dx.doi.org/10.1016/B978-012174698-8/50043-6

Michael, K. (2007). Total Curriculum Management (TCM): An integrated curriculum using distributed content. Retrieved from http://focusonteaching.uow.edu.au/content/groups/public/@web/@cedir/documents/mm/uow038981.pdf

Ornstein, A. C., \& Hunkins, E. P. (2004). Curriculum foundations, principles and issues. USA: Pearson Education.

Ralph, W. (1991). Help! The art of computer technical support. California: Peachpit Press.

Rogers, P. L. (2000). Barriers to adopting emerging technologies in education. Journal of Educational Computing Research, 22(4), 455-472. http://dx.doi.org/10.2190/4UJE-B6VW-A30N-MCE5

Twigg, C. (2000). Who owns online courses and course materials? Intellectual property policies for a new learning environment. New York: Centre for Academic Transformation, Renesselaer Polytechnic Institute.

Vannatta, R. A., \& Fordham, N. (2004). Teacher dispositions as predictors of classroom technology use. Journal 
of Research on Technology in Education, 36(3), 253-271.

Venkatesh, V., Davis, F. D. (2000). A theoretical extension of the technology acceptance model: Four longitudinal field $\quad$ studies. Management $\quad$ Science, $\quad 46(2), \quad 186-204$. http://dx.doi.org/10.1287/mnsc.46.2.186.11926

Venkatesh, V., Morris, M. G., Davis, G. B., \& Davis, F. D. (2003). User acceptance of information technology: Toward a unified view. MIS Quarterly, 27(3), 425-478.

Von Konsky, B. R., Loh, A., Robey, M., Gribble, S. J., Ivins, J., \& Cooper, D. (2006). The benefit of information technology in managing outcomes focused curriculum development across related degree programs. Paper presented at the Eighth Australasian Computing Education Conference (ACE2006), Hobart, Tasmania: Australia.

Watson, E. G., Moloney, P. J., Toohey, S. M., Hughes, C. S. Mobbs, S. L., Leeper, J. B., \& McNeil, H. P. (2007). Development of eMed: A comprehensive, modular curriculum-management system. Academic Medicine, 82(4), 351-360. http://dx.doi.org/10.1097/ACM.0b013e3180334d41

Wood, L. N. (2012). How to align assessment: Learning through a program approach. Australia: Macquarie University. Retrieved from http://staff.mq.edu.au/teaching/teaching_development/resources/

Wood, L. N., Thomas, T., \& Rigby, B. (2011). Assessment and standards for graduate outcomes. Asian Social Science, 7(4), 12-17. http://dx.doi.org/10.5539/ass.v7n4p12 